Article

\title{
Analysis of Derivatized N-Acyl Amino Acid Surfactants Using HPLC and HPLC/MS
}

\author{
Petra Valigurová@, Lenka Jarešová, Jana Váňová and Petr Česla *(i) \\ Department of Analytical Chemistry, Faculty of Chemical Technology, University of Pardubice, Studentská 573, \\ CZ-53210 Pardubice, Czech Republic; st38637@student.upce.cz (P.V.); lenka.jaresova@student.upce.cz (L.J.); \\ jana.vanova@upce.cz (J.V.) \\ * Correspondence: Petr.Cesla@upce.cz; Tel.: +420-466-037-368
}

Received: 9 September 2020; Accepted: 3 October 2020; Published: 8 October 2020

\begin{abstract}
A method for the analysis of weak anionic surfactants based on $\mathrm{N}$-acyl amino acids was developed. The surfactants were derivatized using 2,4'-dibromoacetophenone yielding $4^{\prime}$-bromophenacyl esters suitable for spectrophotometric detection. Surfactants containing glycine, threonine and glutamic acid were analyzed after derivatization using reversed-phase liquid chromatography with UV/Vis and MS detection. The gradient profile was optimized using isocratic retention data of $\mathrm{N}$-acyl-linked fatty acid homologues. The relative content of the homologues of $\mathrm{N}$-acyl-linked fatty acids was expressed using the determined method. The intraday repeatability and stability of the prepared derivatives was tested. The relative content of fatty acids in the surfactants was correlated with the most common sources of fatty acids, showing high Pearson's correlation coefficients with the typical fatty acids profile of a coconut oil.
\end{abstract}

Keywords: amino acid surfactants; 2,4'-dibromoacetophenone; derivatization; reversed phase liquid chromatography; gradient elution

\section{Introduction}

Surfactants are the generally main components of cosmetics, cleaning detergents, emulsions, and other products for household and industrial use. In the case of cosmetic products desired for contact with a human skin, the compounds should possess low irritation potential, hypoallergenicity, and very low cell toxicity. In recent years, biodegradable surfactants based on amino acids have become the major concern for the production of cosmetics. Amino acid surfactants are part of the formulations of shampoos, rinses, body soaps, facial cleansers and many other products, as well as baby care products, due to their ability to create non-irritating creamy foams [1].

The most commonly used amino acid surfactants comprise of an amino acid or a peptide head group residue, responsible for the ionicity of the surfactant and thus its biological activity, and the nonpolar hydrophobic part. The nonpolar part usually represents long chain fatty acids, originated from coconut oil. The majority of the representative fatty acid in coconut oil is lauric acid (C12:0, 49.5\%), followed by myristic acid (C14:0, 19.5\%), palmitic acid (C16:0, 8.5\%), caprylic acid (C8:0, 6.5\%), capric acid (C10:0, 6.0\%), and oleic acid (C18:1, 6.0\%) [2]. These substances are generally used in cosmetics, keeping skin more moistened and healthier hair. Fatty acids used in the production of the surfactants are typically derived from coconut oil or palm oil [3,4]. Some other substrates were reported too, including soybean, corn and olive oils [5], or recently silkworm pupae [6]. The bacterial production of amino acid surfactants can be used for production from sustainable resources, like using the fermentation of cellulosic carbohydrates, i.e., soy hulls as an abundant waste material [7].

Typically, the surfactants produced from natural substrates are complex mixtures, which can contain tens to hundreds of isomers, homologues, or oligomers. Besides the challenging task of the 
purification of the surfactants for some applications including cosmetics [1], the diverse composition is also challenging for the development of methods for their analysis. Due to the complexity of surfactants, separation techniques are usually applied. The nonvolatile nature of most classes of surfactants restricts the direct use of gas chromatography. Consequently, the most analytical methods use high performance liquid chromatography (HPLC), or HPLC coupled with mass spectrometry (LC/MS), as it permits the separation of complex mixtures with a wide distribution of homologues, e.g., alkyl- or ethoxy-ones [8]. In the most research work, atmospheric pressure chemical ionization (APCI) and electrospray ionization (ESI) have been used [9]. Some compounds may, however, partly co-elute and tandem mass spectra can further improve their identification [10]. For the analysis of surfactants, both normal phase and reversed-phase (RP) systems can be used [11-13]. The study of the retention behavior of sulphated oligoethyleneglycol nonylphenyl ether anionic surfactants was presented by Jandera [12]. For the tuning of the retention and solubility of strongly acidic sulphated surfactants, tetraalkylammonium salts were used. Alternatively, the aminopropyl silica gel stationary phase can be used [11]. The most common synthetic anionic surfactants are linear alkylbenzene sulfonates (LAS). These compounds have been found in water from sewage treatment plants and can migrate into the environment. Microwave-assisted extraction and HPLC coupled with fluorescence detection and capillary electrophoresis were used for the analysis by Villar et al. [14]. LC/MS with ESI was used for the identification and quantification of LAS, alkyl ethoxysulfates and alkylsulfates by Lara-Martin et al. [15]. The most often used mobile phases for the analyses of surfactants are acetonitrile with the addition of trifluoroacetic acid, ammonium acetate, or methanol in mixture with water; octadecyl silica gel stationary phases are the most used. Lots of studies have been made with domestic and industrial detergents [14], shampoo and hair conditioners [13], or among the environmentally important samples, in pollutants of leafy and root vegetables [9], or in the sediment and river water samples [15].

In this work, we developed a method for the analysis of $\mathrm{N}$-acyl-linked amino acid weak anionic surfactants after its derivatization with 2,4'-dihydroxyacetophenone. Derivatives of surfactants were qualitatively analyzed using reverse-phase liquid chromatography with UV/Vis and MS detection with a gradient profile optimized using the isocratic retention data of $\mathrm{N}$-acyl-linked fatty acid homologues. The relative content of homologues was correlated with the composition of different types of seed oils, which can be used for the fast screening of the origin of analyzed surfactants.

\section{Materials and Methods}

The anionic surfactants used for the study were Amisoft CS-11, Amisoft CS-22, Amisoft CT-12S, Amisoft ECS-22SB (sodium and triethanolamine salts of N-cocoyl-L-glutamate), Amilite ET-CS-12 (mixture of sodium salts of N-cocyl-L-glutamate and N-cocoyl-L-threoninate), Amilite GCK-12H (potassium salts of $\mathrm{N}$-cocoyl-glycinate and cocoate), and Amilite GCS-12K (sodium salt of $\mathrm{N}$-cocoyl-glycinate). All the surfactants were produced by Ajinomoto (Tokyo, Japan) and kindly donated by the Safic-Alcan Czech Republic. The structures of the surfactants used are shown in Figure 1a. Acetonitrile and 2,4'-dibromoacetophenone were from Sigma-Aldrich (St. Louis, MO, USA), denaturated ethanol and phenolphthalein were from Penta Chemicals (Prague, Czech Republic), and sodium hydroxide was from LachNer (Neratovice, Czech Republic). Deionized water was prepared using the Milli-Q Purification Reference Water System (Millipore, Molsheim, France). 
(a)<smiles>[R]C(=O)NCC(=O)[O-]</smiles><smiles>[R]C(=O)N[C@H](CCC(=O)O)C(=O)O</smiles><smiles>[R]C(=O)N[C@H](C(=O)[O-])[C@@H](C)O</smiles>
glycinate L-glutamate L-threoninate

\section{RCO- fatty acid residue}

(b)<smiles>[R]C(=O)NCC(=O)[O-]</smiles>

Figure 1. (a) Formulas of the anions of analyzed weak anionic surfactants based on glycine, L-glutamic acid, and threonine anions; and (b) the schematic representation of the reaction between the surfactants and $2,4^{\prime}$-dibromoacetophenone.

Samples of weak anionic surfactants were derivatized to obtain UV-absorbing compounds by the following procedure (three replicates were prepared from each sample): $0.5 \mathrm{~mL}$ of liquid samples or $125 \mathrm{mg}$ of solid surfactant was dissolved in $2 \mathrm{~mL}$ of distilled water and $0.5 \mathrm{~mL}$ of ethanol was added to each sample. One hundred and twenty-five milligrams of 2,4'-dibromoacetophenone was added to the samples and closed vials were vigorously shaken and placed for $15 \mathrm{~min}$ in the $70{ }^{\circ} \mathrm{C}$ water bath. After the reaction (Figure 1b), the vials were cooled down to the laboratory temperature and precipitated derivatives were filtered, washed with distilled water and re-dissolved in $1 \mathrm{~mL}$ of acetonitrile before the analysis. The spiked sample of tap water was prepared by mixing of $1 \mathrm{~L}$ of tap water with $0.5 \mathrm{~mL}$ of liquid sample Amilite GCK-12H and sonicated for $15 \mathrm{~min}$. After ultra-sonication, $0.5 \mathrm{~mL}$ of emulsion was derivatized using the aforementioned procedure.

Separations of weak anionic surfactants after derivatization was performed on an Agilent 1200 Rapid Resolution liquid chromatograph equipped with DAD detector (Agilent, Palo Alto, CA, USA). For the LC/MS analysis, Agilent 1260 Infiniti II Prime LC system was used coupled directly with $\mathrm{LC} / \mathrm{MSD}$ iQ detector (single quadrupole type mass spectrometer). The mass spectrometer was operated in positive ionization mode with the following conditions: capillary voltage $3500 \mathrm{~V}$, gas temperature $325^{\circ} \mathrm{C}$, gas flow $11 \mathrm{~L} / \mathrm{min}$ and nebulizer pressure $50 \mathrm{psi}$. The scan range was $70-1200 \mathrm{~m} / \mathrm{z}$, targeted points per second were $3.8 \mathrm{~Hz}$ and the estimated cycle time was $257 \mathrm{~ms} /$ cycle.

The separation of the derivatives of anionic surfactants was performed on a Luna Omega C18 column $(100 \times 2.1 \mathrm{~mm}, 1.6 \mu \mathrm{m}$ fully porous particles; Phenomenex, Torrance, CA, USA) maintained at $40{ }^{\circ} \mathrm{C}$. The mobile phase consisted of water (A) and acetonitrile (B) with the flow rate of $0.5 \mathrm{~mL} / \mathrm{min}$, and an injection volume of $5 \mu \mathrm{L}$. Both the isocratic experiments with 70,80 and $90 \%$ of $\mathrm{B}$ for the determination of retention characteristics of the derivatives and the gradient elution with an optimized profile were used. Optimized gradient profile was as follows: $0 \mathrm{~min}-70 \% \mathrm{~B}, 20 \mathrm{~min}-100 \% \mathrm{~B}$, $27 \mathrm{~min}-100 \% \mathrm{~B}, 28 \mathrm{~min}-70 \% \mathrm{~B}, 30 \mathrm{~min}-70 \% \mathrm{~B}$. Each sample was analyzed in three replicative runs and the results presented are given as the average value and standard deviation.

\section{Results}

Weak anionic surfactants derived from amino acids and fatty acids originated from seed oils are mild and non-irritative compounds. In this work, we focused on the development of a simple method for screening purposes comprising the qualitative analysis of such samples, which are 
composed of $\mathrm{N}$-acyl-glycinate, $\mathrm{N}$-acyl-glutamate and $\mathrm{N}$-acyl-threoninate (Figure 1a). Because of a lack of chromophores necessary for UV/Vis spectrometric detection, we used 2, $4^{\prime}$-dibromoacetophenone as a derivatization agent for the preparation of the corresponding $4^{\prime}$-bromophenacyl esters (Figure 1b).

Reaction of carboxylic acid group with 2,4'-dibromoacetophenone yielding corresponding $4^{\prime}$-bromophenacyl esters is well known for the quantitative determination of fatty acids in several matrices [16,17], however, it is not commonly applied to amino acids samples. In UV spectra, the phenacyl esters exhibit strong absorption bands between 230 and $290 \mathrm{~nm}$, due to the presence of a benzene ring in conjugation with the carbonyl group, and an electronegative bromine atom in para-position on the benzene ring. Based on the obtained spectra, we selected $260 \mathrm{~nm}$ as the detection wavelength of derivatized samples (Figure 2). Within the derivatization process, the samples were typically neutralized using sodium hydroxide solution on phenolphthalein. We tested both the derivatization reaction with and without the neutralization step. Because the surfactants have a very weak acidic character, we obtained similar results for the derivatives prepared after the neutralization of the sample and without neutralization. In the following experiments, the samples were thus derivatized without a neutralization step.

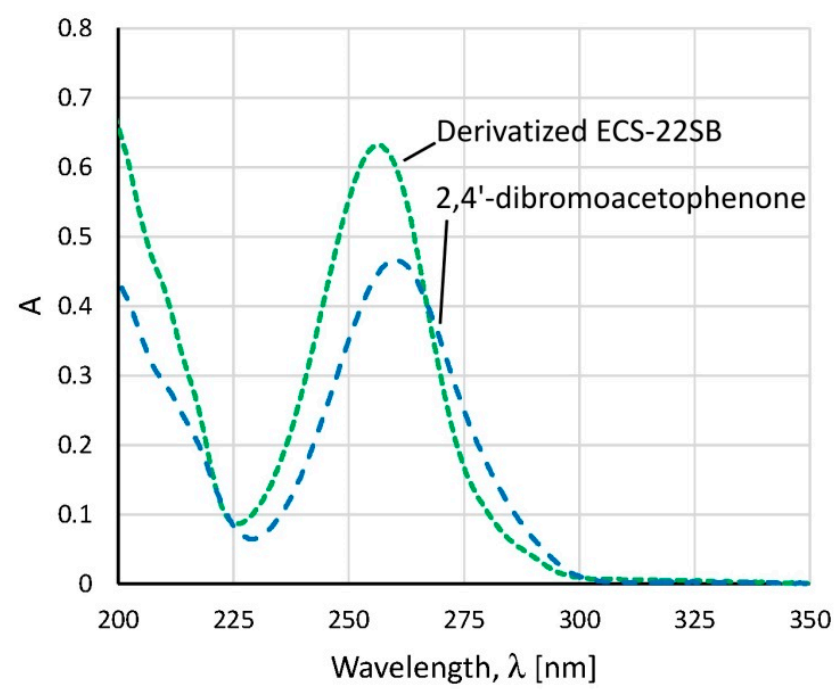

Figure 2. UV spectra of the derivatization agent 2,4'-dibromoacetophenone (blue dashed line) and the derivatized Amisoft ECS-22SB surfactant, containing $N$-acyl-L-glutamate (green dotted line). Both compounds were dissolved in ethanol.

Derivatized samples of the $N$-acyl-amino acid surfactants were analyzed using reversed-phase LC. In the LC/UV chromatograms of the derivatized $N$-acyl-amino acid surfactants, the derivatives of glycinate and threoninate resulted in the separation of mono- $4^{\prime}$-bromophenacyl esters (BPAE) of the surfactants according to the length of their fatty alkyl chains. Surfactants containing caprylic, capric, lauric, myristic, palmitic and oleic fatty acid moieties were identified (Figure 3). For the $\mathrm{N}$-acyl-glutamate derivatives, di-4'-bromophenacyl esters (di-BPAE) of the surfactants were found as well, due to the presence of two carboxylic groups susceptible to the reaction with 2,4'-dibromoacetophenone (Figure 3a). In the chromatogram of a sample containing both $\mathrm{N}$-acyl threoninate and $\mathrm{N}$-acyl-glutamate, two series of derivatives corresponding to the threoninate BPAE and glutamate di-BPAE were found (Figure $3 b$ ). 

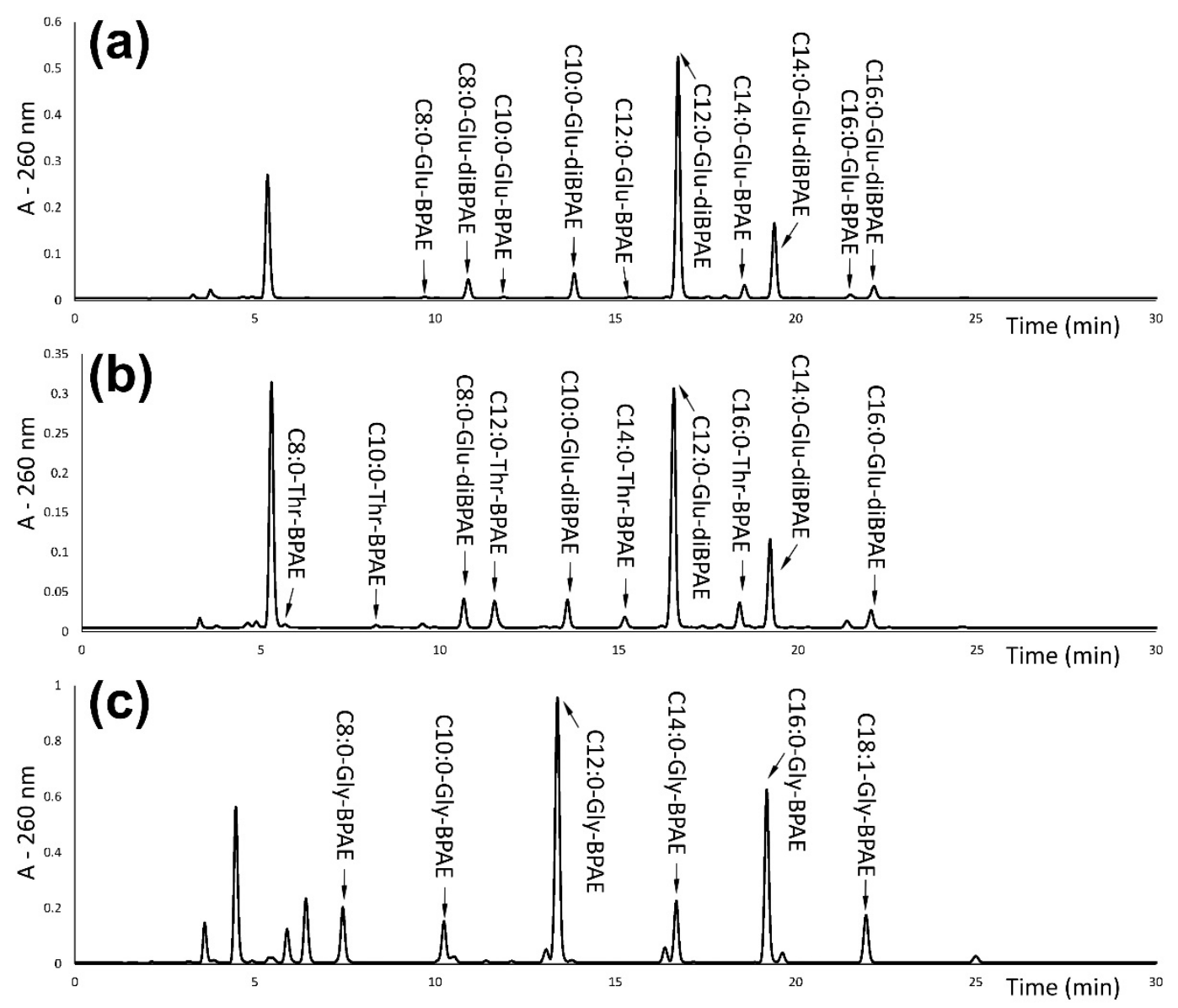

Figure 3. Separation of the $N$-acyl amino acid surfactants after derivatization with 2,4'-dibromoacetophenone, yielding corresponding $4^{\prime}$-bromophenacyl esters (BPAE) a diesters (diBPAE): (a) the Amisoft CS-22 sample containing $N$-acyl glutamate; (b) the Amilite ET-CS-12 sample containing a mixture of $N$-acyl-glutamate and $N$-acyl-threoninate; and (c) the Amilite GCS-12K sample containing $N$-acyl-glycinate.

The identification of fatty acid $N$-acyl-linked amino acid surfactants after the derivatization was based on the evaluation of mass spectra and the corresponding protonated molecules of BPAE (i.e., $\mathrm{m} / \mathrm{z}$ signals $470.2 ; 498.2 ; 526.2 ; 554.2 ; 582.2$ and 610.3 for a series of caprylic to oleic acids linked with glutamic acid), and diBPAE were found (i.e., $\mathrm{m} / \mathrm{z}$ signals $668.1 ; 696.1 ; 724.2 ; 752.2 ; 780.2$ and 808.2 for the same series). The values of the $\mathrm{m} / \mathrm{z}$ are shown in the Supplementary Materials in Tables S1-S3. For some derivatives, adducts with formic acid $[\mathrm{M}+\mathrm{HCOOH}+\mathrm{H}]^{+}$were found as well, with the minor intensity in comparison to the protonated molecule $[\mathrm{M}+\mathrm{H}]^{+}$(approx. $\left.10 \%\right)$. The signals of derivatives BPAE and diBPAE also show typical isotopic distribution for the presence of bromine atoms with a ratio of intensities of $[\mathrm{M}+\mathrm{H}]^{+}$and $[\mathrm{M}+\mathrm{H}]^{+}+2$ signals approx. 1:1 (Figure $\mathrm{S} 1$ ).

Each sample derivative was prepared three times, analyzed by three replicative measurements, and the repeatability of the derivatization reaction was tested. The results of intraday repeatability for using the Amilite GCK-12H sample and tap water spiked with the same sample. The results of the intraday repeatability are shown in Figure 4 as the average relative content of $\mathrm{N}$-acyl-glycinate homologues with the standard deviations. The relative content of the homologues in the sample of the surfactant was expressed as the relative peak area with respect to the sum of peaks of all surfactant homologues observed in the chromatogram. The stability of the derivatives stored one week in a fridge was tested as well for both, GCK-12H sample and the tap water spiked with the GCK-12H sample. Results of the analyses of other surfactants tested are summarized in the Supplementary Materials, Figures S2 and S3. 


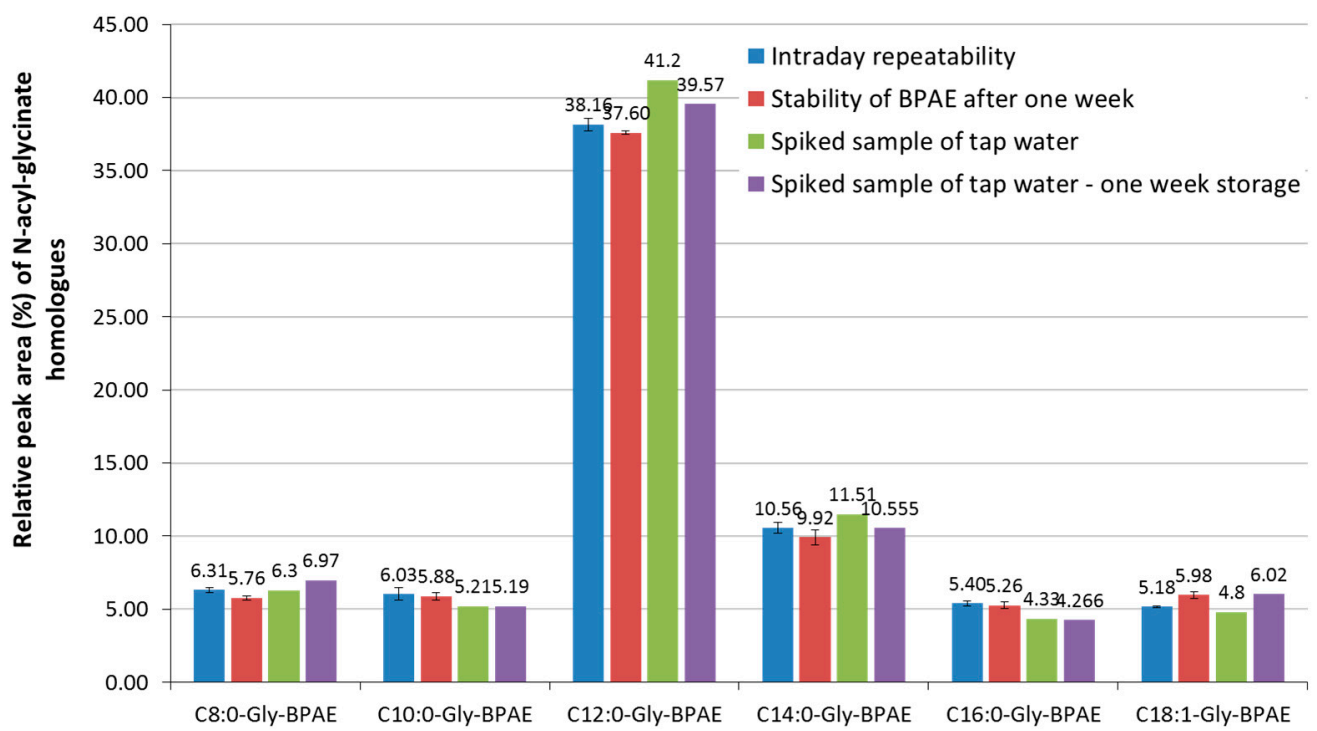

Figure 4. Relative content of $N$-acyl-glycinate homologues (expressed as a relative peak area of a homologue with respect to surfactants in the chromatogram) determined using LC after derivatization with 2,4'-dibromoacetophenone for Amilite GCK-12H sample. Comparison of the intraday repeatability and stability of the derivatives after one week of storage of the $4^{\prime}$-bromophenacyl esters (BPAE). The data are shown as the average value of three repetitive analyses with error bars corresponding to the standard deviations.

\section{Discussion}

The samples of fatty acid $\mathrm{N}$-acyl-linked amino acid weak anionic surfactants can be separated in reversed-phase LC, however, due to the lack of chromophoric groups, the detection with the most commonly used UV/Vis detectors is difficult. With the prepared BPAEs of the surfactants, we achieved separation according to the alkyl chain length of the fatty acid moiety, but also according to the nature of the amino acid presented in the molecule (Figure 3). For the $N$-acyl-glutamate, two carboxylic groups were available for the reaction with 2,4'-dibromoacetophenone yielding both BPAEs and diBPAEs of the $\mathrm{N}$-acyl-glutamate. According to the achieved results, the surplus presence of the derivatization agent led to the prevailing occurrence of diBPAEs with only minor peaks for the BPAEs of $\mathrm{N}$-acyl-glutamate. The reversed-phase separation of the derivatized surfactants exhibited a typical retention order, i.e., increasing retention times with respect to the increasing length of the fatty acid alkyl chain. The retention of the same length of fatty acid and different amino acid type was observed in the order of threoninate $<$ glycinate $<$ glutamate.

Because the absorption in UV/Vis is mainly due to the chromophores of the derivatization agent, prepared derivatives with a different length of fatty acids will exhibit approximately the same molar absorption coefficients, and thus the relative peak areas of the homologues can be considered as corresponding to the relative content of homologues in the samples (relative peak area with respect to all peaks in a chromatogram). According to the peak areas presented in the chromatograms, we constructed a graph shown in Figure 4, describing the relative content of fatty acids. All surfactants studied contained the most abundant peak of $N$-lauroyl amino acids, followed by the fatty acids with lower (caprylic and capric acid) and higher numbers of carbons in the alkyl chain (myristic, palmitic and oleic acids), as shown also in Figures S2 and S3. Such composition corresponds to the typical content of fatty acids in the coconut oil $[2,18]$.

For the developed derivatization method, we also tested the intraday repeatability of the preparation of derivatives and its stability after one week of storage (Figure 4). The mean values of the relative content of different homologues of $\mathrm{N}$-acyl-glycinate was compared and the statistical significance of the differences was tested using the analysis of variance at the probability level $p=0.05$. Statistically significant differences between the values of the relative content of $\mathrm{N}$-acyl-glycinate 
homologues after one week of storage were found only for caprylic acid (C8:0-Gly-BPAE) and oleic acid (C18:1-Gly-BPAE), which indicate the high stability of the derivatives.

In the last part of the work, we focused on the comparison of the results of relative content of $\mathrm{N}$-acyl-amino acid surfactants with different types of sources of fatty acids, which may be potentially used for the synthesis of such compounds. Thus, we plotted the achieved data of the relative content of homologues (relative peak areas of the homologues, Figure 4) with respect to the relative content of fatty acid homologues in coconut oil, palm kernel oil, babasu oil, nut virgin butter and laurel oil, which were found in the literature [18-22]. The correlation of the values is presented in the logarithmic scale, which contributes less to the discrimination of the low abundant fatty acids (Figure 5).

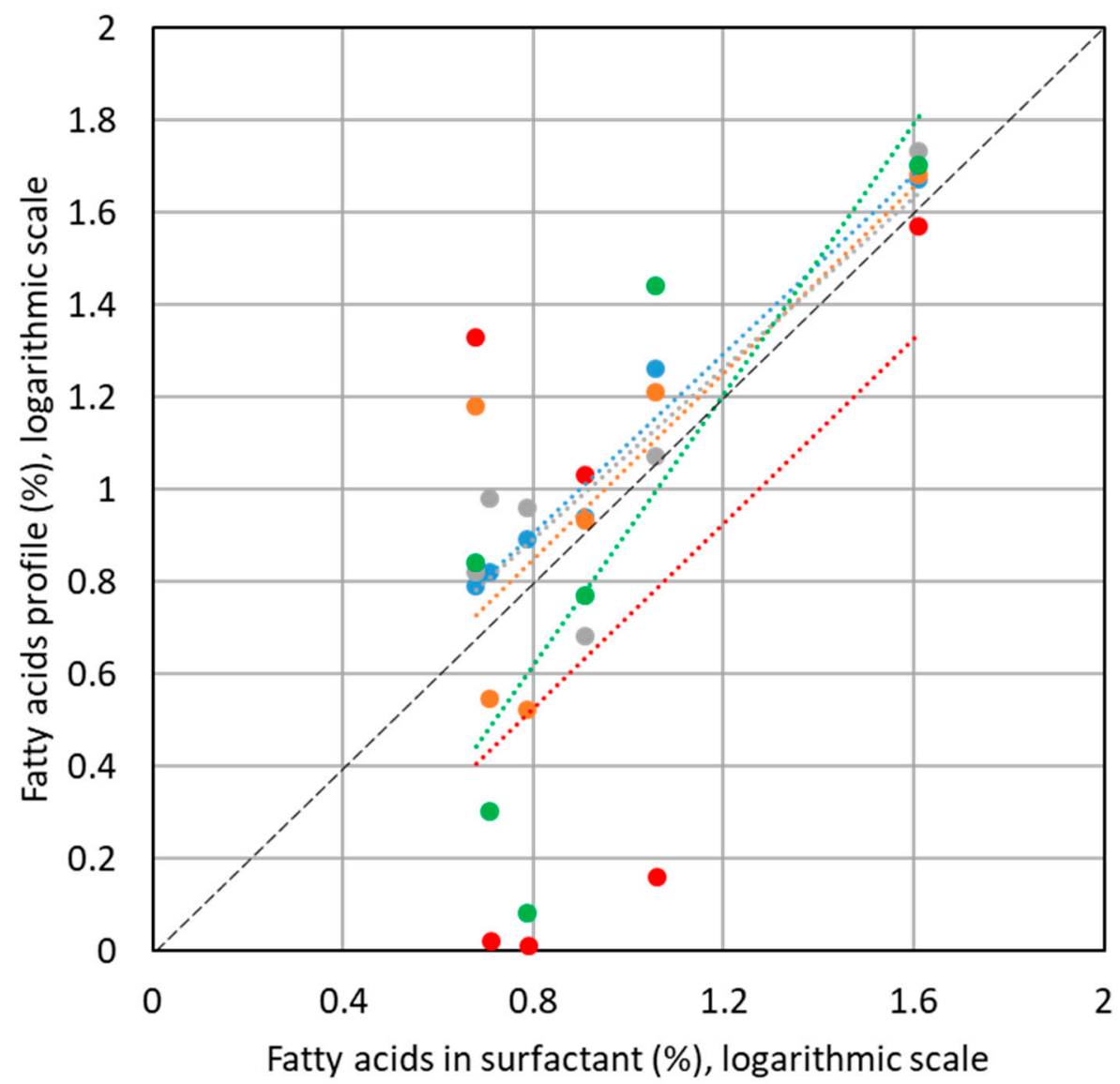

Figure 5. Correlation of the relative content of $N$-acyl homologues in the sample of the Amilite GCK-12H surfactant with the typical relative composition of fatty acids from different sources, based on the literature data (blue-coconut oil [18], orange-palm kernel oil [19], grey-babassu oil [20], green-nut virgin butter [21], red-laurel oil [22]). Data are presented with a logarithmic scale.

For the source of the fatty acids, which corresponds to the best with the studied surfactants, the highest correlation should be obtained with the regression line being closest to the diagonal line of the figure. From the comparison of the plotted data, coconut oil, babasu oil and laurel oil showed the best match of the regression line with the diagonal (blue, red and gray line in the figure). The coefficients of determination for the linear regression line as well as the Pearson's correlation coefficients, however, suggested that the best correlation of the experimentally determined relative content of fatty acid homologues in the $\mathrm{N}$-acyl-amino acid surfactants is achieved with respect to the coconut oil composition. Coefficients of determination yielded 0.9724 for coconut oil, 0.6304 for palm kernel oil, 0.7793 for babasu oil, 0.6591 for nut virgin butter and 0.2435 for laurel oil, respectively. Pearson's correlation coefficients in the same order were 0.9861, 0.7940, 0.8829, 0.8119, and 0.4935. 
Such a fast and simple comparison method can be used for the verification of the origin of surfactant production source.

Supplementary Materials: The following are available online at http://www.mdpi.com/2673-4532/1/1/4/s1, Figure S1: Isotopic pattern of protonated molecule of the $4^{\prime}$-bromophenacyl ester derivative of $N$-lauryl-threoninate surfactant determined using LC/MS, Figure S2: Relative content of $\mathrm{N}$-acyl-glutamate homologues (expressed as relative peak area of a homologue with respect to surfactants in the chromatogram) determined using LC after derivatization with 2,4'-dibromoacetophenone, yielding corresponding di-4'-bromophenacyl esters (diBPAE). The data are shown as average value of three repetitive analyses with error bars as the standard deviations, Figure S3: Relative content of $N$-acyl-amino acid (AA) homologues (expressed as relative peak area of a homologue with respect to surfactants in the chromatogram) determined using LC after derivatization with 2,4'-dibromoacetophenone, yielding corresponding mono- (BPAE) and di-4'-bromophenacyl esters (diBPAE). The data are shown as average value of three repetitive analyses with error bars as the standard deviations, Table S1: Signals for protonated molecules $[\mathrm{M}+\mathrm{H}]^{+}$of native and derivatized $\mathrm{N}$-acyl-glutamate surfactants (CS-11, CS-22, CT-12S, ECS-22SB) with different fatty acid moieties; BPAE $=4$ '-bromophenacyl esters of surfactants, diBPAE $=$ corresponding diesters, Table S2: Signals for protonated molecules $[\mathrm{M}+\mathrm{H}]^{+}$of native and derivatized $\mathrm{N}$-acyl-threoninate surfactant (ET-CS-12) with different fatty acid moieties; BPAE $=4^{\prime}$-bromophenacyl esters of surfactant, Table S3: Signals for protonated molecules $[\mathrm{M}+\mathrm{H}]^{+}$of native and derivatized $\mathrm{N}$-acyl-glycine surfactants (GCK-12H, GCS-12K) with different fatty acid moieties; BPAE = 4'-bromophenacyl esters of surfactants.

Author Contributions: Conceptualization, P.Č.; methodology, P.V. and J.V.; investigation, P.V. and L.J.; data processing, P.V., L.J. and J.V.; writing-original draft preparation, P.V.; writing-review and editing, P.Č. All authors have read and agreed to the published version of the manuscript.

Funding: This research was funded by Czech Science Foundation, grant number 18-14893S.

Acknowledgments: Authors acknowledge the donation of the samples of surfactants from Safic-Alcan Czech Republic (Brno, Czech Republic).

Conflicts of Interest: The authors declare no conflict of interest.

\section{References}

1. Tripathy, D.B.; Mishra, A.; Clark, T.; Farmer, C.R. Synthesis, chemistry, physicochemical properties and industrial applications of amino acid surfactants: A review. C. R. Chim. 2018, 21, 112-130. [CrossRef]

2. Kaunitz, H. Nutritional properties of coconut oil. J. Am. Oil Chem. Soc. 1970, 47, 462A-485A. [CrossRef]

3. Patel, M. Surfactants based on renewable raw materials: Carbon dioxide reduction potential and policies and measures for the European Union. J. Ind. Ecol. 2004, 7, 47-62. [CrossRef]

4. Soo, E.; Salleh, A.B.; Basri, M.; Kamaruddin, K. Optimization of the enzyme-catalyzed synthesis of amino acid-based surfactants from palm oil Fractions. J. Biosci. Bioeng. 2003, 95, 361-367. [CrossRef]

5. Nagao, A.; Kito, M. Synthesis of o-acyl-L-homoserine by lipase. J. Am. Oil Chem. Soc. 1989, 66, 710-713. [CrossRef]

6. Wu, M.H.; Wan, L.Z.; Zhang, Y.Q. A novel sodium N-fatty acyl amino acid surfactant using silkworm pupae as stock material. Sci. Rep. 2014, 4, 1-8. [CrossRef] [PubMed]

7. Reznik, G.O.; Vishwanath, P.; Pynn, M.A.; Sitnik, J.M.; Todd, J.J.; Wu, J.; Jiang, Y.; Keenan, B.; Castle, A.B.; Haskell, R.F.; et al. Use of sustainable chemistry to produce an acyl amino acid surfactant. Appl. Microbiol. Biotechnol. 2010, 86, 1387-1397. [CrossRef] [PubMed]

8. Gonzáles, S.; Petrovic, M.; Barceló, D. Advanced liquid chromatography-mass spectrometry (LC-MS) methods applied to wastewater removal and the fate of surfactants in the environment. Trac-Trends Anal. Chem. 2007, 26, 116-124. [CrossRef]

9. Aparicio, I.; Martin, J.; Abril, C.; Santos, J.L.; Alonso, E. Determination of household and industrial chemicals, personal care products and hormones in leafy and root vegetables by liquid chromatography-tandem mass spectrometry. J. Chromatogr. A 2018, 1533, 49-56. [CrossRef] [PubMed]

10. DeArmond, P.D.; DiGoregorio, A.L. Rapid liquid chromatography-tandem mass spectrometry-based method for the analysis of alcohol ethoxylates and alkylphenol ethoxylates in environmental samples. J. Chromatogr. A 2013, 1305, 154-163. [CrossRef]

11. Jandera, P.; Urbánek, J.; Prokeš, B.; Blažková-Brúnová, H. Chromatographic behaviour of oligoethylene glycol nonyphenyl ether anionic surfactants in normal-phase high-performance liquid chromatography. J. Chromatogr. A 1996, 736, 131-140. [CrossRef] 
12. Jandera, P.; Prokeš, B. Chromatographic behavior of un-sulphated and sulphated oligoethyleneglycol nonylphenyl ether surfactants in normal-phase liquid chromatographic systems containing water. Chromatographia 1996, 42, 539-546. [CrossRef]

13. Im, H.S.; Jeong, Y.H.; Ryoo, J.J. Simultaneous analysis of anionic, amphoteric, nonionic and cationic surfactant mixtures in shampoo and hair conditioner by RP-HPLC/ELSD and LC/MS. Anal. Chim. Acta 2008, 619, 129-136. [CrossRef] [PubMed]

14. Villar, M.; Callejón, M.; Jiménez, J.C.; Alonso, E.; Guiraúm, A. New rapid methods for determination of total LAS in sewage sludge by high performance liquid chromatography (HPLC) and capillary electrophoresis (CE). Anal. Chim. Acta 2009, 634, 267-271. [CrossRef] [PubMed]

15. Lara-Martin, P.A.; Corada-Fernández, C.; Gómez-Parra, A.; González-Mazo, E. Seasonal changes in the concentration of anionic surfactants in estuarine sediments from the River Guadalete (Cadiz, Spain). Sci. Mar. 2010, 74, 125-131. [CrossRef]

16. Reed, A.W.H.; Deeth, H.C.; Clegg, D.E. Liquid chromatographic method for quantitative determination of free fatty acids in butter. J. AOAC Int. 1984, 67, 718-721. [CrossRef]

17. Elliott, J.M.; de Haan, B.; Parkin, K.L. An improved liquid chromatographic method for the quantitative determination of free fatty acids in milk products. J. Dairy Sci. 1989, 72, 2478-2482. [CrossRef]

18. Dayrit, F.M. The properties of Lauric acid and their significance in coconut oil. J. Am. Oil Chem. Soc. 2015, 92, 1-15. [CrossRef]

19. Cunha, V.M.B.; Silva, M.P.; Carvalho, R.N.; Meireles, M.A.A.; Machado, N.T.; Araújo, M.E. lauric acid rich oil supercritical extraction and methodology to predict solubility. Food Pub. Health 2016, 6, 26-32.

20. Ferreira, B.S.; Faza, L.P.; Hyaric, M.L. A comparison of the physicochemical properties and fatty acid composition of Indaiá (Attalea dubia) and Babassu (Orbignya phalerata) oils. Sci. World J. 2012, 3, 1-4. [CrossRef]

21. Fasciotti, M.; Monteiro, T.V.C.; Rocha, W.F.C.; Morais, L.R.B.; Sussulini, A.; Eberlin, M.N.; Cunha, V.S. Comprehensive triacylglycerol characterization of oils and butters of 15 Amazonian oleaginous species by ESI-HRMS/MS and comparison with common edible oils and fats. Eur. J. Lipid Sci. Technol. 2020, 122, 2000019. [CrossRef]

22. Ramadan, A.A.; Mandil, H.H.; Anadani, L. Effect of ripening time of fruits in the chemical composition (\%) of essential oils in Syrian laurel oil. Int. J. Curr. Res. Chem. Pharm. Sci. 2019, 6, 26-34. 